\title{
Perspectives
}

\section{Paroxysmal Nocturnal Hemoglobinuria and the Glycosylphosphatidylinositol Anchor}

\author{
Edward T. H. Yeh and Wendell F. Rosse \\ Department of Medicine, University of Texas, Houston, Texas 77030; and Department of Medicine, Duke University Medical Center, \\ Durham, North Carolina 27710
}

Although the clinical syndrome of paroxysmal nocturnal hemoglobinuria $(\mathrm{PNH})^{1}$ was recognized many years ago (1), its complexity was difficult to explain. The erythrocytes were known to be susceptible to the hemolytic action of complement, and this characteristic formed the basis for the diagnosis of the disease (2). In addition, many patients suffered thromboses and/or had evidence of relative or absolute diminution in hematopoiesis (3). Although the disease appeared to be acquired, no specific lesion could be delineated which could account for the complex clinical symptoms.

The first identified biochemical defects were the absence of two enzymes: acetylcholinesterase from the red cells (4) and alkaline phosphatase from the leukocytes $(5,6)$. Considerably later, the absence of the complement regulatory protein, decay accelerating factor (DAF), was identified (7). To date, at least 14 proteins have been found to be missing or markedly diminished on the abnormal blood cells in PNH ( Table I). For many of these, functions are known, and the lack of those functions may be related to the pathogenesis of $\mathrm{PNH}$; in other cases, the function of the missing protein is not known. Further, it is likely that other proteins, as yet unidentified, are probably also missing.

The recognition, first, that alkaline phosphatase (8) and, later, that DAF (9) were tethered to the plasma membrane by a glycosylphosphatidylinositol anchor directed research on the pathogenesis of the defects in PNH to the biosynthesis of that molecule.

\section{The glycosylphosphatidylinositol anchor and its biosynthesis}

A large number of eukaryotic proteins are attached to the cell surface by novel glycolipids called glycosylphosphatidylinositols (GPIs) (10-13). This type of glycolipid constitutes a

\section{Address correspondence to Edward T. H. Yeh, M.D., Department of Medicine, University of Texas-Houston, 6431 Fannin, Suite 4200, Houston, TX 77030. \\ Received for publication 12 January 1994 and in revised form 31 January 1994.}

1. Abbreviations used in this paper: DAF, decay accelerating factor; DPM, dolichol-phosphate-mannose; ER, endoplasmic reticulum; GPIs, glycosylphosphatidylinositols; PI-PLC, phosphatidylinositolspecific phospholipase C; PNH, paroxysmal nocturnal hemoglobinuria.

J. Clin. Invest.

(c) The American Society for Clinical Investigation, Inc.

$0021-9738 / 94 / 06 / 2305 / 06 \$ 2.00$

Volume 93, June 1994, 2305-2310 minor fraction of total cellular glycolipids and was recognized to be an alternative mechanism for anchoring proteins to the cell membranes only in the late 1970s. The first breakthrough came from the identification of a bacterial phosphatidylinositol-specific phospholipase C (PI-PLC) that could cleave GPIanchored proteins from the cell surface $(8,14)$. Special properties, such as increased translational mobility, phospholipasemediated shedding, apical targeting, and transmembrane signal transduction, have been attributed to GPI-anchored proteins $(10,12,15-17)$. Elucidation of the GPI biosynthetic pathway is a prerequisite to a better understanding of these unique functional properties of GPI-anchored proteins.

The GPI structures of rat brain Thy-1, human erythrocyte acetyl-cholinesterase, and trypanosome variant surface glycoprotein were elucidated in the late 1980 s by nuclear magnetic resonance spectroscopy and fast atom bombardment mass spectroscopy (18-20). They share a remarkably conserved core structure consisting of ethanolamine (ETN)-PO -6 mannose $\alpha$ 1-2 mannose $\alpha 1-6$ mannose $\alpha 1-4$ glucosamine $\alpha 1-6$ inositol (see Fig. 1; the mannose residues are marked M1-M3, and the glucosamine residue is marked $\mathrm{G}$ for future reference). As shown, the ethanolamine phosphate residue is linked by an amide bond to the $\mathrm{COOH}$ terminus of a protein. In mammalian cells, the conserved GPI core can be further modified by addition of ethanolamine phosphate residues to mannose residues M1 or M2 (Fig. 1). The presence of more than one ethanolamine phosphate residue is a distinctive feature of mammalian GPIs. In rat brain Thy-1, a fourth mannose residue is added to $\mathrm{M} 3$, and an $\mathrm{N}$-acetylgalactosamine residue is attached to $\mathrm{M} 1$. The significance of these side chain variations in different GPIs is not known.

An uncommon form of inositol phospholipid, alkylacyl PI, in which an ether linkage is present in the $\mathrm{C} 1$ position of the glycerol backbone, has been found in a large number of mammalian GPIs $(10,12,13,20)$. In contrast, the trypanosomal GPIs use exclusively diacyl PIs. Interestingly, in all mannosylated GPI precursors in mammalian cells, and probably in yeast, there is an additional fatty acid attached to the inositol ring by an ester linkage $(21,22)$. These fatty acylated GPIs are resistant to PI-PLC treatment, but still retain sensitivity to a GPI-specific phospholipase D (21-23). The advantage of fatty acylation during GPI precursor biosynthesis is not known; however, the additional fatty acid is removed after transfer of GPI anchor precursors to proteins. As a result, most of the cell-surface GPI-anchored proteins are sensitive to PI-PLC treatment. In special cases, cell-surface GPI-anchored proteins may still contain the additional fatty acid and are refractory to PI-PLC cleavage. Thus, one must be cautious in using PI-PLC sensitivity as the sole criterion for determining whether or not a protein is GPI anchored. 
Table I. Proteins Known to Be Deficient in Abnormal PNH Cells

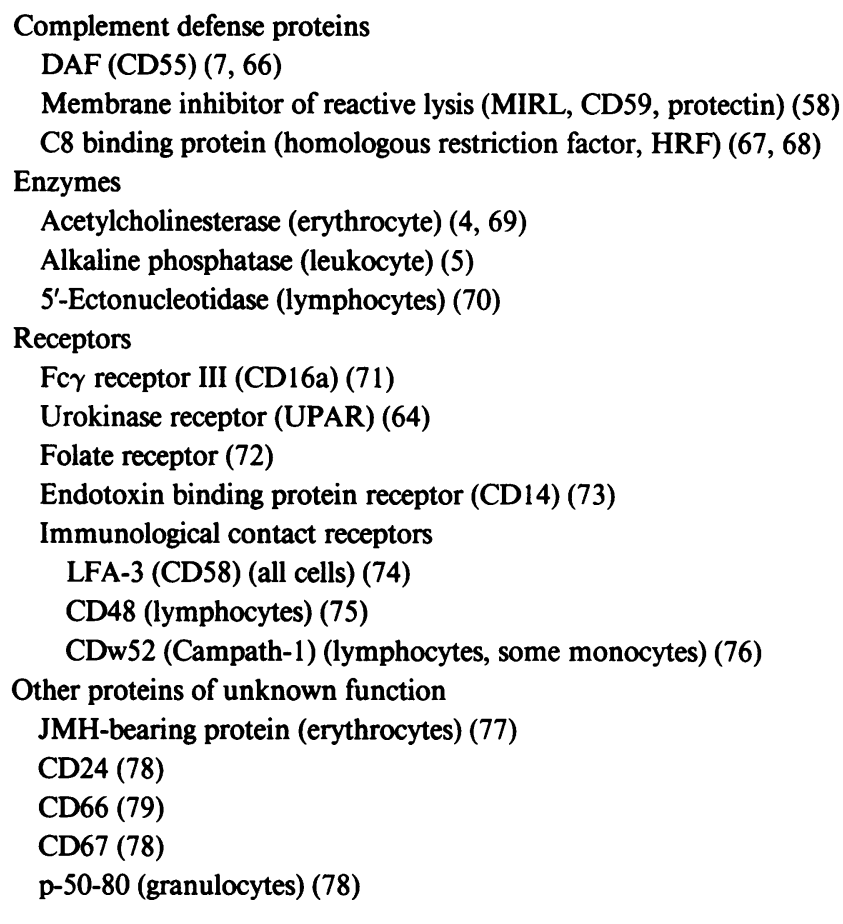

The first step in GPI anchor biosynthesis is the transfer of GlcNAc from UDP-GlcNAc to a phosphoinositol lipid acceptor (PI) to form GlcNAc-PI (Fig. 2). This step is regulated by at least three different genes belonging to the $\mathrm{A}, \mathrm{C}$, and $\mathrm{H}$ complementation classes $(24,25)$. The class $A$ and $H$ cDNAs have been identified by expression cloning techniques $(26,27)$. The human class A cDNA predicts a $54-\mathrm{kD}$ protein of 484 amino acids (26). There is no apparent $\mathrm{NH}_{2}$-terminal leader sequence. Near the $\mathrm{COOH}$ terminus, there is a hydrophobic sequence of 27 amino acids that may act as a transmembrane domain. Thus, it appears to be a type II integral membrane protein with the $\mathrm{NH}_{2}$ terminus present in the cytoplasmic face of the endoplasmic reticulum (ER) membrane.

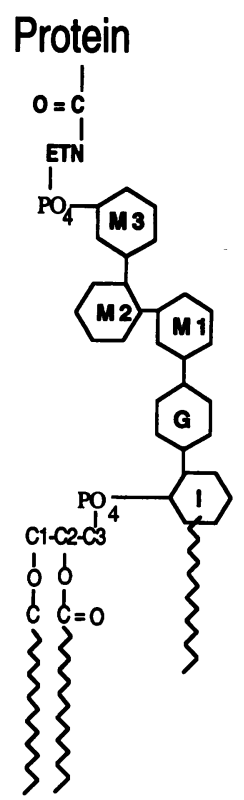

Figure 1. Structure of a GPI-anchored protein. ETN, ethanolamine; M1-3, mannose; $G$, glucosamine; $I$, inositol. Please see text for more detail on modifications that are not shown on this figure.

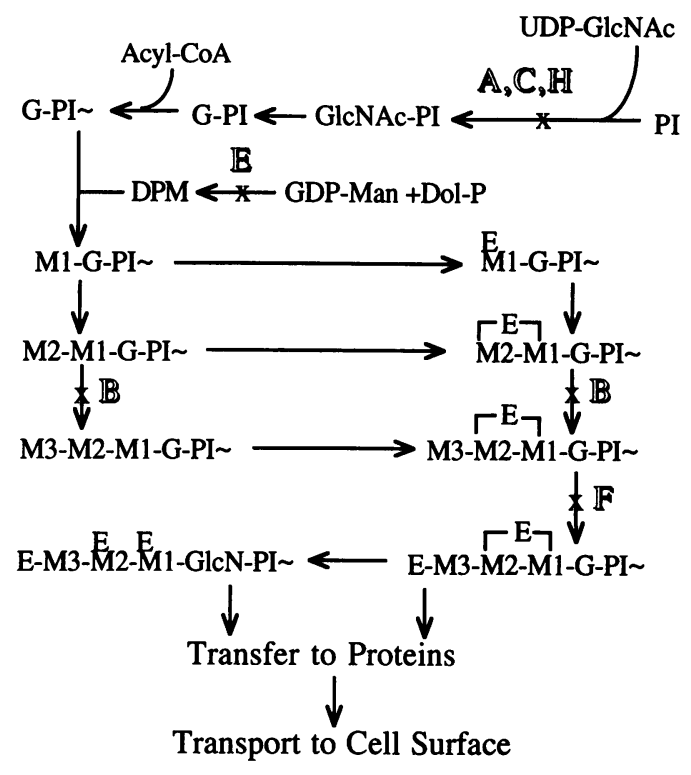

Figure 2. Biosynthesis of the GPI anchor in mammalian cells. PI, phosphoinositol lipid; GlcNAc, $N$-acetylglucosamine; $G$, glucosamine; Dol-P, dolichyl phosphate; $E$ enclosed in brackets indicates isomers which have the ethanolamine phosphate residue attached to either mannose residues M1 or M2. Biosynthetic blocks in Hyman's complementation classes are indicated by $A, B, C, E, F$, and $H(80)$.

The human class $\mathrm{H}$ cDNA predicts a $21-\mathrm{kD}$ protein of 188 amino acids (27). There are no potential $\mathrm{N}$-linked glycosylation sites. Kyte-Doolittle hydropathy plot of the protein suggests that the first and last 30 amino acids are relatively hydrophilic, while the internal core is relatively hydrophobic. The absence of a hydrophobic leader sequence suggests that this protein is not a luminal ER protein. The biphasic, strong hydrophobic stretch between residues 40 and 85 may represent an internal hydrophobic core or a site for interaction with lipid or the hydrophobic regions of other proteins.

These results are consistent with the localization of the first GPI intermediate, GlcNAc-PI, to the cytoplasmic leaflet of the ER membrane bilayer (28). The precise functions of the class $A$ and $\mathrm{H}$ gene products have not yet been identified. Conceivably, they could form an enzyme complex in bringing the hydrophobic PI acceptor and the hydrophilic UDP-GlcNAc donor into close proximity for the transfer to occur.

The second step of GPI anchor biosynthesis is a deacetylation reaction which converts GlcNAc-PI to $\mathrm{GlcNH}_{2}$-PI (G-PI) $(24,25)$. This reaction is enhanced by hydrolysis of GTP $(29)$. The third biosynthetic step is the addition of a fatty acid to the inositol ring to form G-PI (21). Fatty acylated GPIs can no longer be hydrolyzed by PI-PLC, but remain susceptible to GPI-PLD treatment (21). These first three reactions probably occur on the cytosolic leaflet of the ER. The precise step in which GPI intermediates are "flipped" to the luminal side of the ER is not known. One possibility is that G-PI is flipped to the luminal side of the ER to accept mannose donated by dolichol-phosphate-mannose (DPM). A similar process has been postulated in the transport of dolichol-PP-GlcNAc $\mathrm{Man}_{5}$ to the luminal leaflet of the ER to be further mannosylated by DPM.

After fatty acylation of the inositol ring, mannose residues are added sequentially. Since all of the DPM-deficient mutants cannot form mannose-containing GPI precursors, it was assumed that DPM is the mannose donor for the GPI anchor. 
This hypothesis was proven by transfecting into the DPM-deficient mutant the yeast DPM synthase gene $(30,31)$. Reconstitution of the DPM deficiency also permitted mannose addition to the GPI core to proceed and led to reexpression of GPI-anchored proteins on the cell-surface (30), proving that the residue $\mathrm{M} 1$ is donated by DPM. Menon et al. (32) have shown that all of the mannose residues in the trypanosomes are derived from DPM. Mammalian cells most likely also use DPM as the mannose donor for residues $\mathrm{M} 2$ and $\mathrm{M} 3$. The class $\mathrm{B}$ mutant is defective in adding the third mannose residue to the GPI core, thus accumulating GPI intermediates which only contain two mannose residues $(24,33)$.

A major difference between the mammalian and trypanosomal GPIs is the number of ethanolamine phosphate residues attached to the core glycans. The donor for the ethanolamine phosphates is most likely phosphatidylethanolamine $(34,35)$. The completed trypanosome GPI anchor contains a single residue of ethanolamine phosphate attached to M3. In contrast, up to three ethanolamine phosphates may be added to the mammalian GPI core. Furthermore, ethanolamine phosphate can be added to GPI biosynthetic intermediates containing only one or two mannose residues. Thus, the GPI intermediate which accumulates in the class B mutant contains an ethanolamine phosphate residue attached to either $\mathrm{M} 1$ or $\mathrm{M} 2(36,37)$.

The class $\mathrm{F}$ mutant cannot add an ethanolamine phosphate residue to $M 3$ (24), but can add ethanolamine phosphates to either M1 or M2 (36-38). These results suggest that addition of ethanolamine phosphate is regulated by at least two different genes. The importance of having an ethanolamine phosphate attached to M3 is attested by the fact that the class F mutant is unable to express Thy- 1 on the cell surface. Surprisingly, GPIs with a single ethanolamine phosphate residue attached to M3 cannot be detected even in the wild-type cells. This may be because of the rapidity of further ethanolamine phosphate addition or a rapid transfer of GPIs with a single ethanolamine phosphate to proteins (36). Recently, the class F cDNA has been cloned, which predicates a novel hydrophobic polypeptide of 210 amino acids (39).

The preformed GPIs that contain an ethanolamine phosphate residue attached to $\mathrm{M} 3$ are transferred to proteins by a transamidase reaction (40) (Fig. 3). Typically, the precursor to a GPI-anchored protein contains both an $\mathrm{NH}_{2}$-terminal signal peptide and, at the $\mathrm{COOH}$ terminus, a short hydrophobic sequence (15-20 amino acids) which is preceded by a spacer containing 5-10 hydrophilic amino acids. The transamidase has a binding surface for the $\mathrm{COOH}$-terminal hydrophobic peptide. The actual cleavage site is indicated by $\omega$, and the adjacent amino acids by $\omega+1$ and $\omega+2$, respectively. The $\omega$ site is usually occupied by small amino acids: glycine, aspartic acid, asparagine, alanine, serine, or cysteine. The $\omega+2$ site similarly requires small amino acids. However, the $\omega+1$ site has a less stringent requirement for the size of the amino acid. The $\omega$ site is probably positioned near a nucleophilic oxygen in the transamidase, which results in the production of an active carbonyl group. Reaction of the $\mathrm{NH}_{2}$ group on the ethanolamine of the GPI precursor to the activated carbonyl group forms an amide linkage. The GPIs also play a role in activating the transamidase in the cleavage of $\mathrm{COOH}$-terminal signal peptide. In mutant cells, which only make truncated GPIs, cleavage of the $\mathrm{COOH}$-terminal signal peptide of alkaline phosphatase does not occur (41). This cleavage can be reconstituted in vitro by addition of glycolipid preparations containing GPIs derived from wild-type but not mutant cells.

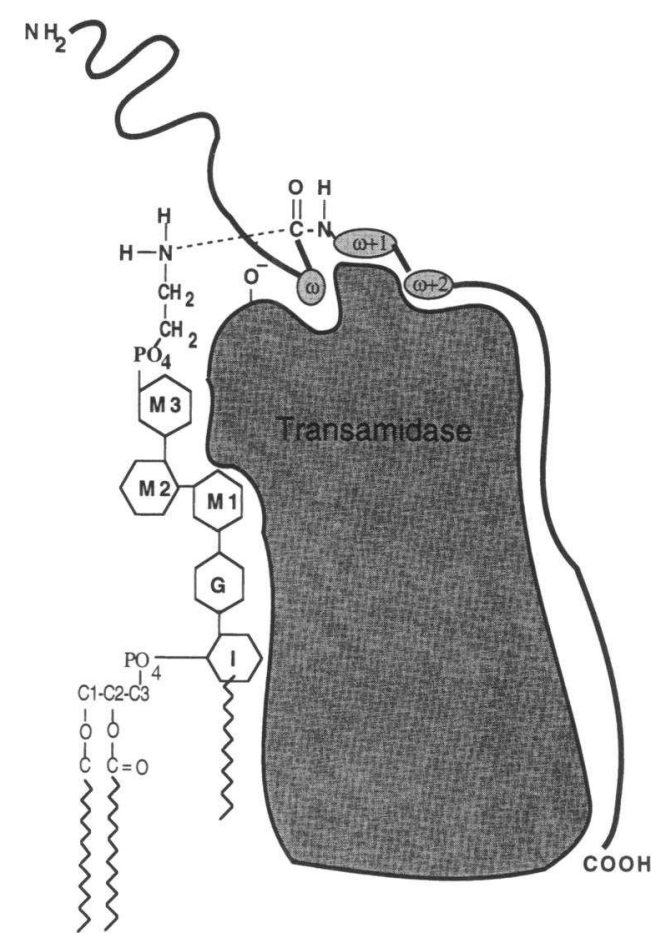

Figure 3. Transfer of the GPI anchor precursors to protein. $\omega$ is the cleavage site. For simplicity, additional ethanolamine phosphate residues attached to mannose residues M1, M2, or both are not shown.

Most cell-surface GPI-anchored proteins are sensitive to PI-PLC treatment, indicating that fatty acid attached to the inositol ring has been removed. A deacylation step must occur either immediately after the transfer of GPIs to the $\mathrm{COOH}$ termini of proteins or later during protein transport. The deacylation step, however, is not active in some cells, such that the surface GPI-anchored proteins remain resistant to PI-PLC treatment (20).

\section{The GPI anchor defect in PNH}

The finding that at least 14 GPI-linked proteins are missing from the abnormal cells in patients with PNH implies clearly that the biosynthesis of the GPI anchor is defective (42). Initial studies showed that the defective granulocytes were not able to make detectable amounts of the core of the anchor (43). Later studies using immortalized lymphocyte cell lines indicated that the defect was before the addition of the first sugar, $N$-acetylglucosamine (44-47). In some patients who had a marked diminution but not an absence of surface expression of GPI-anchored proteins, a small quantity of mannosylated derivatives could be detected.

In all cases $(\sim 40)$ so far investigated by fusion and complementation of either lymphocyte cell lines or granulocytes from peripheral blood or by direct determination of the defect, the defect appears to be the same as the defect in class A of the Thy-1 (-) murine cell lines $(44,45,48-50)$. The defect can be repleted in both murine class $A$ and $\mathrm{PNH}$ lymphocyte cell lines by specific cDNA derived from the PIG-A gene (see above).

The gene encoding this protein has been called the pig-A gene; it is located at the end of the short arm (p21) of the X chromosome in both mice and humans $(26,51)$. Its location on the $\mathrm{X}$ chromosome explains why PNH arises so frequently as the result of an acquired somatic defect since only a single "hit" is necessary for the abrogation of expression; males have 
only one $\mathrm{X}$ chromosome, and in females one of the $\mathrm{X}$ chromosomes has been inactivated by "lyonization" in somatic cells. The genes for two other proteins mediating the biosynthesis of the GPI anchor have been located on autosomal chromosomes; that for PIG-H is on chromosome 14 in humans (27), and that for PIG-F is on chromosome 2 (39).

To date, a number of defects in the pig-A gene have been identified in the abnormal cells of patients with PNH (48-50, 52 ). In some patients, the mRNA is altered in concentration or size; in one such case, an error at the consensus splice site of the fifth exon resulted in a misspliced transcription product (48). In many patients, the defect is the out-of-frame dropping or addition of one or two nucleotides; in all cases, this results in a premature stop codon. Missense mutations have also been identified, but since the function of the protein is not known, it is not certain what the effect of these is on that function. To date, all the identified defects have been in the coding region of the protein, but this may be an artifact of the method of analysis.

Some or all of the abnormal cells of some patients with PNH may have a small amount of the GPI-anchored proteins on the surface $(53,54)$. In some of these patients, these cells appear as a second and distinct population; these cells have been called PNH II cells (53). In other patients, the abnormal cells have a spectrum of surface expression of GPI-linked proteins without evidence of a discrete population (54). The reasons for these differences have not yet been elucidated, but probably are related to defects that result in the production of small amounts of the anchor; such defects could include promoter abnormalities, missense mutations yielding less effective protein products, alternative spicing defects, and defects resulting in unstable mRNA. Although some of these types of defects have been described, there has been no systematic correlation with the presence of type of cells of intermediate abnormality.

When the defect is partial, the anchored proteins are not equally expressed on the surface in both murine cell lines (55) and $\mathrm{PNH}$ granulocytes (56), as, for instance, the $\mathrm{Fc} \gamma$ III receptor (CD16a) appears to be present in larger amounts than CD59 or CD55. Presumably, this is because of the fact that the structure of the protein near the carboxyl terminus that directs the attachment to the anchor is more efficient in CD16 than in CD59.

So far, with one apparent exception (49), the defect has been different in each patient, as one might expect from random mutations. Although the incidence of PNH is not precisely known, it is uncommon but not rare; $>280$ patients have been seen at Duke University alone. It is not certain whether the incidence represents the usual rate of random mutation of a gene or whether the pig-A gene is unusually susceptible to such mutations.

Presumably, the sequence of events leading to the clinical manifestations of PNH begins when some mutagenic event alters the pig-A gene in a single hematopoietic stem cell. For unclear reasons, this gives a proliferative advantage to this cell and its progeny, which then repopulate the marrow to a greater or lesser extent. The erythrocytes that arise from this abnormal clone are hemolyzed by complement during circulation because they lack the GPI-anchored complement defense proteins, $\operatorname{CD} 55(7,57)$ and $\operatorname{CD} 59(58,59)$; this results in anemia, loss of iron through the kidney (60), and, in some patients, damage to the kidneys (61).

The thrombosis characteristic of the disease is thought to be due to abnormalities of the platelets $(62,63)$, which in re- sponse to attack by complement form greater numbers of thrombogenic vesicles than normal cells (63). The receptor for urokinase is lacking on the nucleated blood cells and may also contribute to the thrombotic tendency (64). The other manifestations of the disorder (diminished hematopoiesis, infections, evolution to leukemia, etc. [65]) are less well understood, but are also presumably due to the lack of GPI-linked proteins; many of these may not have been identified yet.

The understanding of the pathogenesis and the identification of the defective gene in PNH may have implications for therapy. It is now clear that the earliest precursors are abnormal (43); it may be possible to remove them and permit the growth of the residual normal appearing clone. It may be possible to transfect the gene into the abnormal cells, thus correcting the defect $(50)$, although the problems of adequate transfection appear to be great at this time.

Many problems remain to be investigated: the nature of the hematopoietic defect, the unusual distribution of the abnormal lymphocytes, the genesis of the partial defect and its importance in understanding the clinical manifestations, the details of the thrombotic tendency, the reason for the evolution to leukemia, etc.

It would have been impossible to predict, 20 or even $10 \mathrm{yr}$ ago, what the fundamental defect in PNH is. Only by application of basic knowledge in an effort to understand the clinical manifestations has some of the mystery of this remarkable disease been unraveled.

\section{References}

1. Strubing, P. 1882. Paroxysmale Hämoglobinurie. Dtsch. Med. Wochenschr. 8:1-8.

2. Ham, T. H., and J. H. Dingle. 1938. Studies on destruction of red blood cells. II. Chronic hemolytic anemia with paroxysmal nocturnal hemoglobinuria: certain immunological aspects of the hemolytic mechanism with special reference to serum complement. J. Clin. Invest. 18:657-672.

3. Dacie, J. V., and S. M. Lewis. 1961. Paroxysmal nocturnal haemoglobinuria: variation in clinical severity and association with bone marrow hypoplasia. Br. J. Haematol. 7:442-457.

4. Auditore, J. V., R. C. Hartmann, J. M. Flexner, and O. J. Balchum. 1960. The erythrocyte acetylcholinesterase enzyme in paroxysmal nocturnal hemoglobinuria. Arch. Pathol. 69:534-540.

5. Beck, W. S., and W. N. Valentine. 1951. Biochemical studies on leucocytes. II. Phosphatase activity in chronic lymphatic leukemia, acute leukemia, and miscellaneous hematologic conditions. J. Lab. Clin. Med. 38:245-253.

6. Lewis, S. M., and J. V. Dacie. 1965. Neutrophil (leucocyte) alkaline phosphatase in paroxysmal nocturnal haemoglobinuria. Brit. J. Haematol. 11:549557.

7. Nicholson-Weller, A., J. P. March, S. I. Rosenfeld, and K. F. Austen. 1983. Affected erythrocytes of patients with paroxysmal nocturnal hemoglobinuria are deficient in the complement regulatory protein, decay accelerating factor. Proc. Natl. Acad. Sci. USA. 80:5430-5434.

8. Low, M. G., and J. B. Finean. 1977. Release of alkaline phosphatase from membranes by a phosphatidylinositol-specific phospholipase C. Biochem. J. 167:281-284.

9. Davitz, M. A., M. G. Low, and V. Nussenzweig. 1986. Release of decay-accelerating factor (DAF) from the cell membrane by phosphatidylinositol-specific phospholipase C (PIPLC). J. Exp. Med. 163:1150-1161.

10. Cross, G. A. M. 1990. Glycolipid anchoring of plasma membrane proteins. Annu. Rev. Cell Biol. 6:1-39.

11. Ferguson, M. A. J., and A. F. Williams. 1988. Cell-surface anchoring of proteins via glycosyl-phosphatidylinositol structures. Annu. Rev. Biochem. 57:285-320.

12. Englund, P. T. 1993. The structure and biosynthesis of glycosyl-phosphatidylinositol protein anchors. Annu. Rev. Biochem. 62:121-138.

13. Low, M. G., and A. R. Saltiel. 1988. Structural and functional roles of glycosyl-phosphatidylinositol in membranes. Science (Wash. DC). 239:268-275.

14. Ikzawa, H., M. Yamanegi, R. Taguchi, R. Miyagita, and T. Ohyabu. 1976. Studies on phosphatidylinositol phospholipase (phospholipase C type) of Bacillus cereus. I. Purification, properties, and phosphatase releasing activity. Biochim. Biophys. Acta. 450:154-164. 
15. Low, M. G. 1989. Glycosyl-phosphatidylinositol: a versatile anchor for cell surface proteins. FASEB (Fed. Am. Soc. Exp. Biol.) J. 3:1600-1608.

16. Yeh, E. T. H., H. Reiser, A. Bamezai, and K. L. Rock. 1988. TAP transcription and phosphatidylinositol linkage mutants are defective in activation through the T cell receptor. Cell. 52:665-674.

17. Lisanti, M. P., M. Sargiacomo, L. Greave, A. R. Saltiel, and E. RodriguezBoulan. 1988. Polarized apical distribution of glycosyl-phosphatidylinositol-anchored proteins in a renal epithelial cell line. Proc. Natl. Acad. Sci. USA. 85:95579561 .

18. Roberts, W. L., S. Santikarn, V. N. Reinhold, and T. L. Rosenberry. 1988. Structural characterization of the glycoinositol phospholipid membrane anchor of human erythrocyte acetylcholinesterase by fast atom bombardment mass spectrometry. J. Biol. Chem. 263:18776-18784.

19. Homans, S. W., M. A. J. Ferguson, R. A. Dwek, T. W. Rademacher, R. Anand, and A. F. Williams. 1988. Complete structure of the glycosylphosphatidylinositol membrane anchor of rat brain Thy-1 glycoprotein. Nature (Lond.). 333:269-272.

20. Roberts, W. L., J. J. Myher, A. Kuksis, M. G. Low, and T. L. Rosenberry. 1988. Lipid analysis of the glycoinositol phospholipid membrane anchor of human erythrocyte acetylcholinesterase. J. Biol. Chem. 263:18766-18775.

21. Urakaze, M., T. Kamitani, R. DeGasperi, E. Sugiyama, H. M. Chang, C. D. Warren, and E. T. H. Yeh. 1992. Identification of a missing link in glycosylphosphatidylinositol anchor biosynthesis in mammalian cells. J. Biol. Chem. 267:6459-6462.

22. Costello, L. C., and P. Orlean. 1992. Inositol acylation of a potential glycosyl phosphoinositol anchor precursor from yeast requires acylcoenzyme A J. Biol. Chem. 267:8599-8603.

23. Davitz, M. A., D. Hereld, S. Shak, J. Krakow, P. T. Englund, and V. Nussenzqeig. 1987. A glycan-phosphatidylinositol-specific phospholipase D in human serum. Science (Wash. DC). 238:81-88.

24. Sugiyama, E., R. DeGasperi, M. Urakaze, H. M. Chang, L. J. Thomas, R. Hyman, C. D. Warren, and E. T. H. Yeh. 1991. Identification of defects in glycosylphosphatidylinositol anchor biosynthesis in the Thy-1 expression mutants. J. Biol. Chem. 266:12119-12122.

25. Stevens, V. L., and C. R. H. Raetz. 1991. Defective glycosylphosphatidylinositol biosynthesis in extracts of three Thy- 1 negative lymphoma cell mutants. J. Biol. Chem. 266:10039-10042.

26. Miyata, T., J. Takeda, Y. Iida, N. Yamada, N. Inoue, M. Takahashi, K. Maeda, T. Kitani, and T. Kinoshita. 1993. The cloning of PIG-A, a component in the early step of GPI-anchor biosynthesis. Science (Wash. DC). 259:1318-1320

27. Kamitani, T., H. M. Chang, C. Rollins, G. Waneck, and E. T. H. Yeh. 1993. Correction of the class $\mathrm{H}$ defect in glycosylphosphatidylinositol anchor biosynthesis in Ltk-cells by a cloned human cDNA. J. Biol. Chem. 268:2073320736.

28. Vidugiriene, J., and A. K. Menon. 1993. Early lipid intermediates in glycosyl-phosphatidylinositol anchor assembly are synthesized in the ER and located in the cytoplasmic leaflet of the ER membrane bilayer. J. Cell Biol. 121:987-996.

29. Stevens, V. L. 1993. Regulation of glycosylphosphatidylinositol biosynthesis by GTP. Stimulation of $N$-acetylglucosamine-phosphatidylinositol deacetylation. J. Biol. Chem. 268:9718-9724.

30. DeGasperi, R., L. J. Thomas, E. Sugiyama, H. M. Chang, P. J. Beck, P Orlean, C. Albright, G. Waneck, J. F. Sambrook, and C. D. Warren. 1990. Correction of a defect in mammalian GPI anchor biosynthesis by a transfected yeas gene. Science (Wash. DC). 250:988-991.

31. Orlean, P., C. Albright, and P. W. Robbins. 1988. Cloning and sequencing of the yeast gene for dolichol phosphate mannose synthase, an essential protein J. Biol. Chem. 263:17499-17507.

32. Menon, A. K., S. Mayor, and R. T. Schwarz. 1990. Biosynthesis of glycosyl-phosphatidylinositol lipids in Trypanosoma brucei: involvement of mannosyl-phosphoryldolichol as the mannose donor. EMBO (Eur. Mol. Biol. Organ.) J. 9:4249-4258.

33. Puoti, A., C. Desponds, C. Frankhauser, and A. Conzelmann. 1991. Characterization of a glycophospholipid intermediate in the biosynthesis of glycophosphatidylinositol anchors accumulating in the Thy-1 negative lymphoma line S1A-b. J. Biol. Chem. 266:21051-21059.

34. Menon, A. K., and V. Stevens. 1992. Phosphatidylethanolamine is the donor of the ethanolamine residue linking a glycosylphosphatidylinositol anchor to protein. J. Biol. Chem. 267:15277-15280.

35. Menon, A. K., M. Eppinger, S. Mayor, and R. T. Schwarz. 1993. Phosphatidylethanolamine is the donor of the terminal phosphoethanolamine group in trypanosome glycosylphosphatidylinositols. EMBO (Eur. Mol. Biol. Organ.) J. 12:1907-1914.

36. Kamitani, T., A. K. Menon, Y. Hallaq, C. D. Warren, and E. T. H. Yeh. 1992. Complexity of ethanolamine phosphate addition in the biosynthesis of glycosylphosphatidylinositol anchors in mammalian cells. J. Biol. Chem. 267:24611-24619.

37. Hirose, S., G. M. Prince, D. Sevlever, L. Ravi, T. L. Rosenberry, E. Ueda, and M. E. Medof. 1992. Characterization of putative glycoinositol phospholipid anchor precursors in mammalian cells. Localization of phosphoethanolamine. $J$. Biol. Chem. 267:16968-16974.
38. Pouti, A., and A. Conzelmann. 1993. Characterization of abnormal free glycophosphatidylinositols accumulating in mutant lymphoma cells of class B, E, F, and H. J. Biol. Chem. 268:7215-7224.

39. Inooue, N., T. Kinoshita, T. Orii, and J. Takeda. 1993. Cloning of a human gene, PIG-F, a component of glycosylphosphatidylinositol anchor biosynthesis, by a novel expression cloning strategy. J. Biol. Chem. 268:6882-6885.

40. Udenfriend, S., R. Micanovic, and K. Kodukula. 1991. Structural requirements of a nascent protein for processing to a PI-G anchored form: studies in intact cells and cell-free systems. Cell Biol. Int. Rep. 15:739-759.

41. Kodukula, K., R. Amthauer, D. Cines, E. T. H. Yeh, L. Brink, L. J. Thomas, and S. Udenfriend. 1992. Biosynthesis of phosphatidylinositol-glycan (PI-G)-anchored membrane proteins in cell-free systems: PI-G is an obligatory co-substrate for $\mathrm{COOH}$-terminal processing of nascent proteins. Proc. Natl. Acad. Sci. USA. 889:4982-4985.

42. Rosse, W. F. 1990. Phosphatidylinositol-linked proteins and paroxysmal nocturnal hemoglobinuria. Blood. 75:1595-1601.

43. Mahoney, J. F., M. Urakaze, S. Hall, R. DeGasperi, H. M. Chang, E Sugiyama, C. D. Warren, M. Borowitz, A. Nicholson Weller, W. F. Rosse, and E. T. H. Yeh. 1992. Defective glycosylphosphatidylinositol anchor synthesis in paroxysmal nocturnal hemoglobinuria granulocytes. Blood. 79:1400-1403.

44. Armstrong, C., J. Schubert, E. Ueda, J. J. Knez, D. Gelperin, S. Hirose, R. Silber, S. Hollan, R. E. Schmidt, and M. E. Medof. 1992. Affected paroxysmal nocturnal hemoglobinuria $T$ lymphocytes harbor a common defect in assembly of $\mathrm{N}$-acetyl-D-glucosamine inositol phospholipid corresponding to that in class $\mathrm{A}$ Thy-1-murine lymphoma mutants. J. Biol. Chem. 267:25347-25351.

45. Norris, J., S. Hall, R. E. Ware, T. Kamitani, H.-M. Chang, E. T. H. Yeh, and W. F. Rosse. 1994. The defect in glycosylphosphatidylinositol anchor synthesis in paroxysmal nocturnal hemoglobinuria. Blood. 83:816-821.

46. Takahashi, M., J. Takeda, S. Hirose, R. Hyman, N. Inoue, T. Miyata, E. Ueda, T. Kitani, M. E. Medof, and T. Kinoshita. 1993. Deficient biosynthesis of $N$-acetylglucosaminyl-phosphatidylinositol, the first intermediate of glycosyl phosphatidylinositol anchor biosynthesis, in cell lines established from patients with paroxysmal nocturnal hemoglobinuria. J. Exp. Med. 177:517-521.

47. Hillmen, P., M. Bessler, P. J. Mason, W. M. Watkins, and L. Luzzatto. 1993. Specific defect in $\mathrm{N}$-acetylglucosamine incorporation in the biosynthesis of the glycosylphosphatidylinositol anchor in cloned cell lines from patients with paroxysmal nocturnal hemoglobinuria. Proc. Natl. Acad. Sci. USA. 90:52725276.

48. Takeda, J., T. Miyata, K. Kawagoe, Y. lida, Y. Endo, T. Fujita, M. Takahashi, T. Kitani, and T. Kinoshita. 1993. Deficiency of the GPI anchor caused by a somatic mutation of the PIG-A gene in paroxysmal nocturnal hemoglobinuria. Cell. 73:703-711.

49. Miyata, T., N. Yamada, Y. Iida, J. Nishimura, J. Takeda, T. Kitani, and T. Kinoshita. 1994. Abnormalities of PIG-A transcripts in granulocytes from patients with paroxysmal nocturnal hemoglobinuria. N. Engl. J. Med. 330:249-255.

50. Bessler, M., P. J. Mason, P. Hillmen, T. Miyata, N. Yamada, J. Takeda, L. Luzzatto, and T. Kinoshita. 1994. Paroxysmal nocturnal hemoglobinuria (PNH) is caused by somatic mutations of the PIG-A gene. EMBO (Eur. Mol. Biol. Organ.) J. 13:110-117.

51. Ware, R. E., T. A. Howard, T. Kamitani, H.-M. Chang, E. T. H. Yeh, and M. F. Seldin. 1994. Chromosomal assignment of genes involved in glycosylphosphatidylinositol anchor biosynthesis: implications for the pathogenesis of paroxysmal nocturnal hemoglobinuria. Blood. In press.

52. Ware, R. E., T. A. Howard, J. Norris, S. Hall, and W. F. Rosse. 1993. A novel frameshift mutation in the human PIG-A gene in a patient with paroxysma nocturnal hemoglobinuria. Blood. 82(Suppl. 1):310a. (Abstr.)

53. Rosse, W. F., J. P. Adams, and A. M. Thorpe. 1974. The population of cells in paroxysmal nocturnal haemoglobinuria of intermediate sensitivity to complement lysis: significance and mechanism of increased immune lysis. $B r . J$. Haematol. 28:181-190.

54. Rosse, W. F., S. Hoffman, M. Campbell, M. Borowitz, J. O. Moore, and C. J. Parker. 1991. The erythrocytes in paroxysmal nocturnal haemoglobinuria of intermediate sensitivity to complement lysis. Br. J. Haematol. 79:99-107.

55. Thomas, L. J., M. Urakaze, R. DeGasperi, T. Kamitani, E. Sugiyama, H.-M. Chang, C. D. Warren, and E. T. H. Yeh. 1992. Differential expression of glycosylphosphatidylinositol-anchored proteins in a murine $\mathrm{T}$ cell hybridoma mutant producing limiting amounts of the glycolipid core. Implications for paroxysmal nocturnal hemoglobinuria. J. Clin. Invest. 89:1172-1177.

56. Edberg, J. C., J. E. Salmon, M. Whitlow, and R. P. Kimberly. 1991. Preferential expression of human $\mathrm{Fc} \mathrm{RIII}_{\mathrm{PMN}}(\mathrm{CD} 16)$ in paroxysmal nocturnal hemoglobinuria. Discordant expression of glycosyl phosphatidylinositol-linked proteins. J. Clin. Invest. 87:58-67.

57. Medof, M. E., A. Gottlieb, T. Kinoshita, S. Hall, R. Silber, V. Nussenzweig, and W. F. Rosse. 1987. Relationship between decay accelerating factor deficiency, diminished acetylcholinesterase activity, and defective terminal complement pathway restriction in paroxysmal nocturnal hemoglobinuria erythrocytes. J. Clin. Invest. 80:165-174.

58. Holguin, M. H., L. R. Frederick, N. J. Bernshaw, L. A. Wilcox, and C. J. Parker. 1989. Isolation and characterization of a membrane protein from normal human erythrocytes that inhibits reactive lysis of the erythrocytes of paroxysmal nocturnal hemoglobinuria. J. Clin. Invest. 84:7-17. 
59. Holguin, M. H., L. A. Wilcox, N. J. Bernshaw, W. F. Rosse, and C. J. Parker. 1989. Relationship between the membrane inhibitor of reactive lysis and the erythrocyte phenotypes of paroxysmal nocturnal hemoglobinuria. J. Clin. Invest. 84:1387-1394.

60. Sears, D. A., P. R. Anderson, A. L. Foy, H. L. Williams, and W. H. Crosby. 1966. Urinary iron excretion and renal metabolism of hemoglobin in hemolytic diseases. Blood. 28:708-725.

61. Clark, D. A., S. A. Butler, V. Braren, R. C. Hartmann, and D. E. Jenkins, Jr. 1981. The kidneys in paroxysmal nocturnal hemoglobinuria. Blood. 57:8389.

62. Aster, R. H., and S. E. Enright. 1969. A platelet and granulocyte membrane defect in paroxysmal nocturnal hemoglobinuria: Usefulness for the detection of platelet antibodies. J. Clin. Invest. 48:1199-1210.

63. Wiedmer, T., S. E. Hall, T. L. Ortel, W. H. Kane, W. F. Rosse, and P. J. Sims. 1993. Complement-induced vesiculation and exposure of membrane prothrombinase sites in platelets of paroxysmal nocturnal hemoglobinuria. Blood. 82:1192-1196.

64. Ploug, M., T. Plesner, E. Ronne, V. Ellis, G. Hoyer Hansen, N. E. Hansen, and K. Dano. 1992. The receptor for urokinase-type plasminogen activator is deficient on peripheral blood leukocytes in patients with paroxysmal nocturnal hemoglobinuria. Blood. 79:1447-1455.

65. Rosse, W. F., and C. J. Parker. 1985. Paroxysmal nocturnal haemoglobinuria. Clin. Haematol. 14:105-125.

66. Pangburn, M. K., R. D. Schreiber, and H. J. Muller-Eberhard. 1983. Deficiency of an erythrocyte membrane protein with complement regulator activity in paroxysmal nocturnal hemoglobinuria. Proc. Natl. Acad. Sci. USA. 80:5430-5434.

67. Zalman, L. S., L. M. Wood, M. M. Frank, and H. J. Müller-Eberhard. 1987. Deficiency of the homologous restriction factor in paroxysmal nocturnal hemoglobinuria. J. Exp. Med. 165:572-577.

68. Hänsch, G. M., S. Schönermark, and D. Roelcke. 1987. Paroxysmal nocturnal hemoglobinuria type III. Lack of an erythrocyte membrane protein restricting the lysis of C5b-9. J. Clin. Invest. 80:7-12.

69. Kunstling, T. R., and W. F. Rosse. 1969. Erythrocyte acetylcholinesterase deficiency in paroxysmal nocturnal hemoglobinuria (PNH). A comparison of the complement-sensitive and insensitive populations. Blood. 33:607-616.
70. Misumi, Y., S. Ogata, K. Ohkubo, S. Hirose, and Y. Ikehara. 1990. Primary structure of human placental 5'-nucleotidase and identification of the glycolipid anchor in the mature form. Eur. J. Biochem. 181:563-569.

71. Selvaraj, P., W. F. Rosse, R. Silber, and T. A. Springer. 1988. The major Fc receptor in blood has a phosphatidylinositol anchor and is deficient in paroxysmal nocturnal haemoglobinuria. Nature (Lond.). 333:565-567.

72. Antony, A. C. 1992. The biological chemistry of folate receptors. Blood. 79:2807-2820.

73. Simmons, D. L., S. Tan, D. G. Tenen, A. Nicholson-Weller, and B. Seed. 1989. Monocyte antigen CD14 is a phospholipid anchored membrane protein. Blood. 73:284-289.

74. Selvaraj, P., M. L. Dustin, R. Silber, M. G. Low, and T. A. Springer. 1987. Deficiency of lymphocyte function-associated antigen 3 (LFA-3) in paroxysmal nocturnal hemoglobinuria. Functional correlates and evidence for a phosphatidylinositol membrane anchor. J. Exp. Med. 166:1011-1025.

75. Schubert, J., M. Alvarado, P. Uciechowski, M. Zielinska Skowronek, M. Freund, H. Vogt, and R. E. Schmidt. 1991. Diagnosis of paroxysmal nocturnal haemoglobinuria using immunophenotyping of peripheral blood cells. $\mathrm{Br} . \mathrm{J}$. Haematol. 79:487-492.

76. Nagakura, S., T. Kawagauchi, K. Horikawa, M. Hidaka, N. Iwamoto, K. Takasuki, and H. Nakakuma. 1994. A deficiency of CDw52 (Campath-1 antigen) of paroxysmal nocturnal hemoglobinuria lymphocytes. Blood. 82:3790-3792.

77. Bobolis, K. A., J. J. Moulds, and M. J. Telen. 1992. Isolation of the JMH antigen on a novel phosphatidylinositol-linked human membrane protein. Blood. 79:1574-1581.

78. van der Schoot, C. E., T. W. Huizinga, E. T. van't Veer-Korthof, R. Wijmans, J. Pinkster, and A. E. von dem Borne. 1990. Deficiency of glycosylphosphatidylinositol-linked membrane glycoproteins of leukocytes in paroxysmal nocturnal hemoglobinuria; description of a new diagnostic cytofluorometric assay. Blood. 76:1853-1859.

79. Mayne, K. M., K. Pulford, M. Jones, K. Micklem, G. Nagel, C. E. van der Schoot, and D. Y. Mason. 1993. Antibody Byl14 is selective for the 90 kD PI-linked component of the CD66 antigen; a new reagent for the study of paroxysmal nocturnal haemoglobinuria. Br. J. Haematol. 83:30-38.

80. Hyman, R. 1988. Somatic genetic analysis of the expression of cell surface molecules. Trends Genet. 4:5-8. 